\title{
Que Perfil da Família Biológica e Adotante, e da Criança Adotada Revelam os Processos Judiciais?
}

\author{
What's the Profile of the Biological, Adopting Families and Adopted Child as Revealed by \\ the Judicial Processes?
}

\author{
Fernanda Neísa Mariano* \& Maria Clotilde Rossetti-Ferreira \\ Universidade de São Paulo, Ribeirão Preto, Brasil
}

\begin{abstract}
Resumo
A adoção de crianças necessita ser estudada em seus aspectos legais, psicológicos, socioculturais. Este estudo tem o objetivo de caracterizar as crianças, as famílias adotantes e biológicas, envolvidas em processos de adoção em Ribeirão Preto-SP, de 1991 a 2000. Cento e dez processos judiciais foram analisados através de uma estatística descritiva. Constatou-se a prevalência das adoções "prontas", nas quais os adotantes requerem na Justiça a adoção de uma criança, que conheceram através de mediadores ou em instituições. Os adotantes pertencem às camadas médias e populares e apresentam diferentes motivações para a adoção, entre elas a infertilidade e o vínculo com a criança. As famílias biológicas provêm das camadas populares e fazem uso da rede de apoio para manter seus filhos; quando esta se esgota, entregam-nos em adoção. Este estudo mostra tanto a necessidade de compreender as adoções "prontas" como as motivações para a entrega de um filho para adoção.

Palavras-chaves: Adoção; Família adotante; Psicologia Jurídica.
\end{abstract}

\begin{abstract}
The adoption of children needs to be studied in its legal, psychological, social and cultural aspects. The purpose of this study is to characterize the children, the birth and adopting families involved in adoption processes in Ribeirão Preto - SP, from 1991 to 2000. One-hundred ten judicial processes were analyzed through descriptive statistics. Most of the adoptions that prevailed were those of the "ready" type; in which the adopting ones go through the judicial system for the adoption of a child, who they met through mediators or institutions. The adopting families belong to middle and lower classes and have different motivations for the adoption, like infertility and bond established with the child. The biological families belong to the lower classes and make use their social network to support their children. When this help is worn out, they hand their children over for adoption. This study shows the need to understand of the "ready" adoptions as well as what motivates biological families to give a child up for adoption

Keywords: Adoption; adopting family; Judicial Psychology.
\end{abstract}

O instituto da adoção é muito recente no Brasil. Somente no início do século passado, a partir do Código Civil de 1917, a adoção de crianças e adolescentes somente foi regulamentada. No entanto, ela sempre existiu como prática social na família brasileira. Mesmo depois de sua regulamentação, a adoção continuou se dando, muitas vezes, de formas e caminhos "alternativos" àqueles preconizados pela lei. Isso pode ocorrer na forma da inserção de crianças na família, criadas como filhos, sem a busca da Justiça para a aquisição de vínculo filial, os chamados "filhos de criação", como também com as crianças que vivem temporariamente sob o cuidado de uma ou mais famílias no

\footnotetext{
"Endereço para correspondência: Universidade de São Paulo, Faculdade de Filosofia, Ciências e Letras de Ribeirão Preto, Av. Bandeirantes, 3900 , Bloco C, Ribeirão Preto, SP, 14040-901.E-mail: femarian@hotmail.com; mcrferre@usp.br Agradecemos às contribuições das professoras Dra. Marília Spósito, Dra. Ana Paula Soares da Silva, Dra. Kátia Amorim de Souza e ao apoio concedido pela Fundação de Amparo à Pesquisa do Estado de São Paulo (FAPESP) e pelo Conselho Nacional de Desenvolvimento Científico e Tecnológico (CNPq)
}

decorrer de sua infância e adolescência, tendo uma ou várias mães, fenômeno denominado "circulação de crianças" por Fonseca (2002).

Em termos legais, a adoção constitui-se em uma das formas de colocação de crianças e/ou adolescentes em uma família substituta. A adoção pressupõe a perda do poder familiar pelos pais biológicos e a aquisição de um novo vínculo de filiação pela criança, o que não ocorre na guarda, na tutela e nas práticas sociais acima referidas - que não são regulamentadas pela lei e não serão objeto deste estudo.

Com a promulgação do Estatuto da Criança e do Adolescente (ECA), em 1990, amplia-se o leque de características que passa a ser aceito em relação aos candidatos à adoção, no que diz respeito ao estado civil e à idade. Assim, a adoção é possível de ser requisitada por qualquer pessoa maior de 21 anos de idade, independentemente de seu estado civil, desde que haja diferença de 16 anos entre adotante e adotado, não sendo permitida a adoção por familiares (avós e irmãos do adotando). O ECA estabelece, desta forma, diferentes possibilidades de adoção: a adoção 
unilateral ou monoparental (quando um dos cônjuges ou concubinos adota o filho do companheiro, nascido de relacionamento anterior), adoção conjunta (por casais ou concubinos) e adoção singular (pessoas solteiras, viúvas, divorciadas ou separadas judicialmente). Ainda, embora não seja uma prática definida juridicamente, existem as adoções "prontas" ou diretas. Nessas adoções, os pais biológicos e/ou mediadores entregam a criança a um casal ou pessoa solteira, viúva ou separada, a qual, já estando com a criança, procura a Vara da Infância e Juventude a fim de regularizar a situação adotiva. Essa intermediação da adoção pode ser feita por conhecidos das mães e/ou dos adotantes, familiares, profissionais que trabalham em hospitais, ou até mesmo através de abrigos ou outras instituições comunitárias.

As motivações dos adotantes para receberem uma criança na condição de filho em sua família é um aspecto bastante pesquisado e usualmente recebe grande atenção dos profissionais do Judiciário, ao acompanharem as adoções. No estudo realizado por Weber (2003), através da análise de 240 questionários respondidos por pais adotivos, de diversos Estados brasileiros, a principal motivação apresentada para a adoção foi a infertilidade. Becker (2002), Cassin (2000), Santos e Pereira (1999) referem-se a alguns aspectos observados nas motivações para a adoção, os quais podem influenciar o sucesso ou não dos processos adotivos. Entre eles, os autores citam a maneira como os adotantes lidam com o luto pela infertilidade e pelo tão desejado filho biológico que não conseguiram gestar e que papéis atribuem à criança adotada. Brito e Diuana (2002), que estudaram especificamente as adoções unilaterais, apontaram para o crescente número dessa modalidade de adoção e encontraram algumas motivações subjacentes a elas: adotantes que requereram seus enteados em adoção, a fim de atribuírem a eles próprios o papel de pai, legitimarem o papel de educador e minimizarem conflitos dentro da nova família que foi constituída. Outras vezes, o pedido da adoção funda-se na necessidade de apagar ou vingar-se do genitor da criança, após separações conflituosas. Com essas constatações, as autoras apontam a necessidade de se avaliar as reais vantagens dessas adoções, dado o direito da criança de conhecer sua origem e de ter sua identidade assegurada, o que muitas vezes acaba não ocorrendo.

$\mathrm{Na}$ literatura brasileira, alguns protagonistas das adoções têm sido mais estudados do que outros. Os pais biológicos são a temática de um menor número de pesquisas, em comparação aos pais adotivos, às crianças adotadas e às equipes profissionais. Dentre as pesquisas brasileiras sobre os pais biológicos, há estudos sócio-demográficos, como os de Freston e Freston (1994) e Oliveira (2002). O primeiro estudo foi realizado em um hospital universitário, com 58 mães que entregaram seus filhos para adoção, tendo-se concluído que a escolha feita por essas mães foi determinada pela conjugação de fatores econômicos com fatores familiares - enfraquecimento da família extensa com a migração e/ou ausência de um companheiro. Já o estudo de Oliveira, que analisou 133 processos de adoção e relacionou todos os fatores da entrega das crianças para adoção, afirma que os principais fatores foram a falta de apoio familiar $(42 \%$ dos processos), o fato de a mãe não ter condições socioeconômicas e habitacionais para ficar com o filho (15\%) e a criança ser fruto de relacionamento fortuito (11\%).

Como alguns desses elementos indicam, a prática da adoção encontra-se permeada por aspectos complexos que vão estar presentes tanto nas adoções como na entrega das crianças por seus pais biológicos. Entre estes aspectos estão as negociações entre as partes envolvidas, as novas configurações de família no Brasil, a ausência de políticas públicas, as diferentes concepções de maternidade e paternidade presentes em nosso ideário, entre outros. Para subsidiar melhor a compreensão desses processos, possibilitando traçar políticas públicas e reformulações legais relativas a essa questão, é necessário uma apreensão ampla do panorama das adoções que vêm ocorrendo no país, os diferentes cenários envolvidos (jurídico, famílias, abrigos, grupos de apoio, etc.), com vários protagonistas (crianças, famílias adotivas e biológicas e profissionais da área, dentre outros) e as diversas práticas discursivas. Com esse objetivo, o Centro de Investigações sobre Desenvolvimento Humano e Educação Infantil (CINDEDI) vem desenvolvendo uma série de pesquisas articuladas sobre essa temática, através de trabalhos que procuram conhecer essa situação a partir de diferentes focos. Dentre esses, encontra-se o presente estudo (Mariano, 2004).

Este teve por meta mapear, a partir do cenário da Justiça, as adoções que ocorreram no município de Ribeirão Preto, no período de 1991 a 2000. Para isto, procurou-se caracterizar as crianças, os pais adotantes e biológicos envolvidos nesses processos. Nessa caracterização, além de aspectos sócio-demográficos, buscou-se compreender os motivos elencados pelos adotantes para adoção dessas crianças, bem como os relacionados à entrega destas pelos pais biológicos. Outro propósito do estudo foi, através do perfil dos envolvidos e de alguns indicadores, apreender as práticas sociais que estão ou podem estar relacionadas à adoção e à entrega de crianças.

\section{Procedimentos Metodológicos}

\section{Material}

Foram analisados 110 processos de adoção, do período de 1991 a 2000, do Fórum da Comarca de Ribeirão Preto. Para a realização dessa pesquisa foram seguidos os procedimentos éticos estipulados pela Resolução 196/96, do Conselho Nacional da Saúde sobre Pesquisas com Seres Humanos. Especificamente, foi necessária a autorização do Corregedor do Estado de São Paulo, bem como do Juiz da Vara da Infância e da Adolescência de Ribeirão Preto SP. Além da não identificação das pessoas envolvidas nos processos judiciais, a pesquisadora comprometeu-se ainda em realizar apenas uma análise quantitativa sobre os processos, conforme a determinação da Corregedoria.

\section{Procedimentos}

Os 110 processos analisados foram escolhidos de maneira aleatória segundo uma tabela que gerava números (Silva, 1998). Para a realização da coleta de dados, foram 
criadas várias fichas referentes aos documentos constituintes dos processos, aos adotantes, aos pais biológicos, às crianças, aos aspectos gerais dos processos, além das decisões, motivos, solicitações e procedimentos apresentados pelos representantes da Justiça, pela Promotoria e pelos profissionais da equipe interdisciplinar (psicólogos e assistentes sociais).

A coleta dos dados foi realizada no Arquivo Geral do Fórum da Comarca de Ribeirão Preto. Para o armazenamento dos dados e sua posterior análise, utilizou-se o banco de dados Epiinfo, criado pela Organização Mundial de Saúde (OMS).

\section{Resultados}

\section{As Crianças Adotadas}

A caracterização das crianças adotadas é muito pobre em decorrência da falta de registro nos processos. Dessa forma, os dados que puderam ser apreendidos referem-se à idade, à etnia, à ocorrência ou não de institucionalização e de vitimização dessas crianças. Dos 110 processos analisados, $60 \%$ eram referentes a meninos $(n=66)$ que estavam sendo requeridos em adoção e $40 \%$ a meninas $(n=44)$. Destas crianças, $70 \%$ tinham até um ano de idade.

Como a faixa etária das crianças foi um indicador freqüentemente registrado, pôde-se comparar o perfil das crianças adotadas nas diferentes modalidades de adoção e constatou-se que entre as adoções "prontas" e as realizadas por cadastrados não há diferença significativa - 89\% dos cadastrados e $78 \%$ dos requerentes de adoções "prontas" adotaram crianças com até dois anos de idade. No entanto, a adoção unilateral distingue-se das demais modalidades de adoção, pelo fato de que $46 \%$ das crianças foram adotadas até dois anos e as demais (54\%) foram requeridas em adoção após essa idade.

A etnia das crianças foi registrada em apenas 25 processos, embora essa seja considerada uma característica relevante pelos profissionais da área judiciária.

Das 110 crianças referidas nos processos, 17 (15,5\%) ficaram institucionalizadas antes de serem colocadas em família substituta. E, em 16 processos $(14,5 \%)$, foi registrada a ocorrência de pelo menos uma modalidade de maustratos contra a criança no período anterior à sua adoção, sendo a negligência $(n=10)$ e a violência física $(n=7)$ as formas mais freqüentes.

\section{Os Pais Adotantes}

Em relação aos adotantes, há uma maior quantidade de dados em comparação aos dos demais protagonistas crianças e famílias biológicas; o que permite uma melhor caracterização (Tabela 1).

Tabela 1

Caracterização dos Adotantes segundo a Idade, Estado Civil, Escolaridade e Atividade Profissional

\begin{tabular}{|c|c|c|c|c|}
\hline \multirow[t]{2}{*}{ Variável } & \multicolumn{2}{|c|}{ Adoções "prontas" } & \multicolumn{2}{|c|}{ Adoções por Cadastrados } \\
\hline & $\begin{array}{l}\text { Homens } \\
\mathrm{f}(\%)\end{array}$ & $\begin{array}{l}\text { Mulheres } \\
\mathrm{f}(\%)\end{array}$ & $\begin{array}{l}\text { Homens } \\
\mathrm{f}(\%)\end{array}$ & $\begin{array}{l}\text { Mulheres } \\
\mathrm{f}(\%)\end{array}$ \\
\hline Idade & $\mathrm{n}=70$ & $\mathrm{n}=77$ & $\mathrm{n}=16$ & $\mathrm{n}=17$ \\
\hline $21-25$ & $3(4,5)$ & $5(6,5)$ & $1(6,25)$ & $2(11,5)$ \\
\hline $26-30$ & $4(5,5)$ & $13(17,0)$ & $2(12,5)$ & $5(29,5)$ \\
\hline $31-35$ & $15(21,5)$ & $19(24,5)$ & $6(37,5)$ & $5(29,5)$ \\
\hline $36-40$ & $12(17,0)$ & $14(18,0)$ & $5(31,25)$ & $2(11,5)$ \\
\hline $41-45$ & $12(17,0)$ & $7(9,0)$ & $1(6,25)$ & $1(6,0)$ \\
\hline $46-50$ & $9(13,0)$ & $11(14,5)$ & $1(6,25)$ & $1(6,0)$ \\
\hline$>51$ & $15(21,5)$ & $8(10,5)$ & $o$ & $1(6,0)$ \\
\hline Estado Civil & $\mathrm{n}=71$ & $\mathrm{n}=78$ & $\mathrm{n}=15$ & $\mathrm{n}=17$ \\
\hline Solteiro & $O$ & $4(5,0)$ & $o$ & $2(12,0)$ \\
\hline Amasiado & $12(17,0)$ & $13(16,5)$ & $O$ & o \\
\hline Casado & $58(81,5)$ & $57(73,0)$ & $15(100)$ & $15(88,0)$ \\
\hline Separado & $O(O)$ & $1(1,5)$ & $O$ & $O$ \\
\hline Divorciado & $1(1,5)$ & $3(4,0)$ & $O$ & $o$ \\
\hline Escolaridade & $\mathrm{n}=4.5$ & $\mathrm{n}=40$ & $\mathrm{n}=15$ & $\mathrm{n}=16$ \\
\hline Sem estudo & $o$ & $2(5,0)$ & $o$ & $6(4,5,0)$ \\
\hline Ensino fundamental incompleto & $21(46,5)$ & $21(52,5)$ & $5(33,5)$ & $1(5,0)$ \\
\hline Ensino Fundamental & $3(6,5)$ & $7(17,5)$ & $O$ & $1(5,0)$ \\
\hline Ensino Médio incompleto & $2(4,5)$ & $1(2,5)$ & $2(13,5)$ & $o$ \\
\hline Ensino Médio & $8(18,0)$ & $12(30,0)$ & $3(20,0)$ & $4(25,0)$ \\
\hline Ensino Superior incompleto & $4(9,0)$ & $2(5,0)$ & $1(6,5)$ & $1(5,0)$ \\
\hline Ensino Superior & $7(15,5)$ & $6(15,0)$ & $4(2,5)$ & $3(15,0)$ \\
\hline Atividade Profissional & $\mathrm{n}=71$ & $\mathrm{n}=75$ & $\mathrm{n}=16$ & $\mathrm{n}=16$ \\
\hline Trabalhadores manuais não qualificados & $5(7,0)$ & $11(14,5)$ & $o$ & $o$ \\
\hline Donas de casa & $o$ & $27(36,0)$ & $O$ & $7(44,0)$ \\
\hline Trabalhadores semi-especializados & $33(46,5)$ & $18(24,0)$ & $4(25,0)$ & $4(25,0)$ \\
\hline Trabalhadores especializados & $31(43,5)$ & $19(25,5)$ & $11(69,0)$ & $5(31,0)$ \\
\hline Atividades mal definidas & $2(3,0)$ & $O$ & $1(6,0)$ & $o$ \\
\hline
\end{tabular}


Considerando a modalidade de adoção, a maioria (72,7\%) são adoções "prontas" ou diretas, através das quais os adotantes $(n=80)$ solicitaram a regulamentação da adoção de uma criança, que fora recebida diretamente da família biológica ou de outras maneiras, sem a mediação da Justiça. As adoções unilaterais e as realizadas por cadastrados ocorreram aproximadamente com a mesma freqüência. Em $15,5 \%$ dos processos $(n=17)$, os adotantes estavam cadastrados na lista de espera por crianças em adoção existentes nos Fóruns das Comarcas brasileiras. E em 11,8\% dos processos, os adotantes $(n=13)$ realizaram adoções unilaterais, ou seja, eles estavam pleiteando a adoção de filhos de seus companheiros(as) ou cônjuges.

Na modalidade de adoção unilateral, devido à sua pequena representação e por sua peculiaridade em relação às outras modalidades, a caracterização dos adotantes será apresentada com poucos indicadores.

No geral, em relação aos adotantes, há características semelhantes entre os requerentes das diferentes modalidades de adoção: a maioria é casada ou amasiada, e vive em união há um longo período. Na maioria das adoções "prontas", os adotantes tinham mais de 10 anos de vida em comum $(70 \%)$, enquanto que os cadastrados tinham entre quatro e nove anos de união (50\%).

Os requerentes cadastrados eram mais jovens que os que requereram adoções "prontas". Entre os cadastrados no Fórum, $80 \%$ das mulheres tinham até 40 anos de idade e, nessa mesma proporção, os homens apresentavam até 50 anos. Já nas adoções "prontas", 80\% das adotantes tinham até 50 anos de idade e os adotantes tinham 55 anos.

Outro indicador interessante a ser mencionado referese à existência ou não de outros filhos, que nos possibilita observar que a maioria dos cadastrados não os tinha, enquanto que os requerentes das adoções "prontas” já eram pais. Se, por um lado, 50\% dos requerentes de adoções "prontas" ou diretas tinham entre um a três filhos, 14\% possuíam mais do que quatro e, aproximadamente, $30 \%$ não tinham filhos; por outro, $65 \%$ dos cadastrados pelo Fórum não tinham filhos.

Na Figura 1, ao relacionar-se os motivos para a adoção, apresentam-se dois grupos de adotantes dentre as adoções "prontas": aqueles que adotaram por uma série de aspectos relacionados à existência de vínculo com a criança (49,5\%); e, aqueles que o fizeram por infertilidade ou problemas de saúde (35\%). Entretanto, a maioria dos adotantes cadastrados pelo Fórum (71\%) adotou devido a questões de saúde que dificultaram ou impossibilitaram a concepção de filhos. E, nas adoções unilaterais, vários motivos foram apresentados, sendo que o principal deles foi a vinculação já existente com a criança (100\%), seguido pela preocupação em garantir os direitos sucessórios e beneficiários da criança (38\%), e pelo casamento com o (a) genitor (a) da criança (46\%). Esses motivos são muito específicos e diferenciaram essa modalidade de adoção das demais.

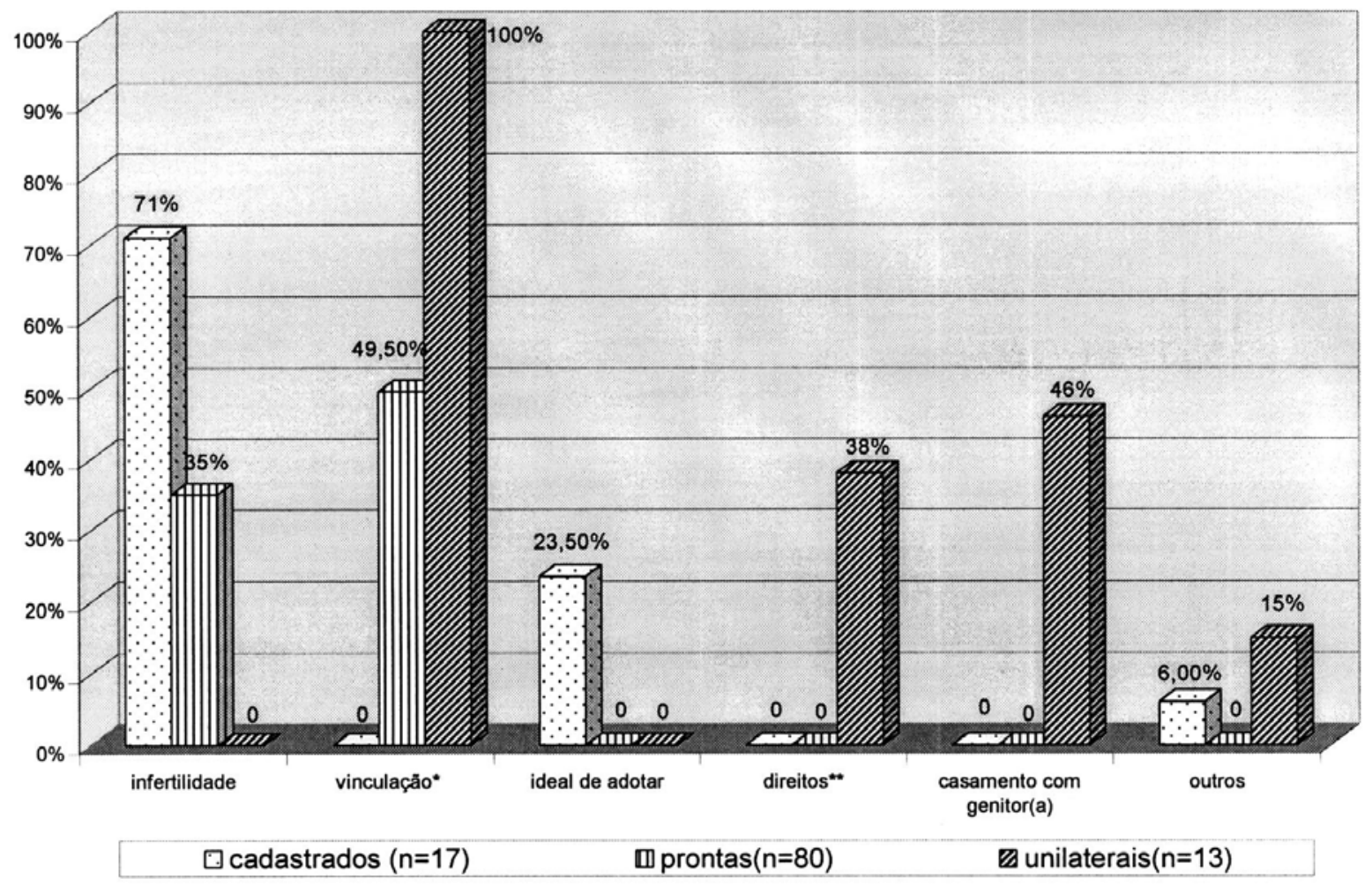

Figura 1. Motivos apresentados pelos adotantes para a realização das diferentes modalidades de adoção:

* vinculação afetiva com a criança; *** direitos sucessórios e beneficiários. 
Em relação ao perfil socioeconômico dos adotantes, os indicadores relacionados à escolaridade e à atividade profissional desenvolvida apontam que, tanto os cadastrados como os requerentes das adoções "prontas", são provenientes das camadas médias e populares. Os adotantes cadastrados parecem ter condições socioeconômicas próprias das camadas médias, possuindo um maior grau de escolaridade ( $27 \%$ com terceiro grau) e exercendo atividades que requerem maior especialização (70,5\%). Entre os que realizaram "adoções prontas", $14 \%$ tinham o terceiro grau, $48 \%$ realizavam atividades de menor qualificação e $39 \%$ desempenhavam atividades especializadas.

Considerou-se o local de moradia como outro indicador para confirmar a hipótese de que os adotantes são pertencentes às camadas médias e populares. Tanto requerentes das adoções "prontas" como os adotantes cadastrados residem, principalmente, nas zonas norte e oeste da cidade, bairros em que há a maior concentração de chefes de família que possuem renda mensal entre um e dez salários mínimos (Prefeitura Municipal de Ribeirão Preto, 2003).

\section{Os Pais Biológicos}

Entre os envolvidos nas adoções, os pais biológicos foram os menos descritos nas peças processuais. Em apenas 31 processos foram encontrados indicadores sobre os pais e, pela pouca representatividade, não serão apresentados neste trabalho. Já sobre as mães, obtiveram-se informações em 77 processos; entretanto, os dados obtidos foram registrados de maneira descontínua e sem sistematização (Tabela 2). Alguns indicadores não serão apresentados neste trabalho pela falta de registro como, por exemplo, a etnia dessas mães. Da mesma forma, o registro descontínuo dos indicadores resultou em baixas freqüências, que, se divididas pelas três modalidades de adoção, gerariam amostras muito pequenas, o que impediria comparações confiáveis. Conseqüentemente, os indicadores sobre as mães biológicas e das crianças serão apresentados de maneira geral.

Tabela 2

Caracterização das Mães Biológicas segundo a Idade, Estado Civil, Escolaridade, Moradia e Atividade Profissional

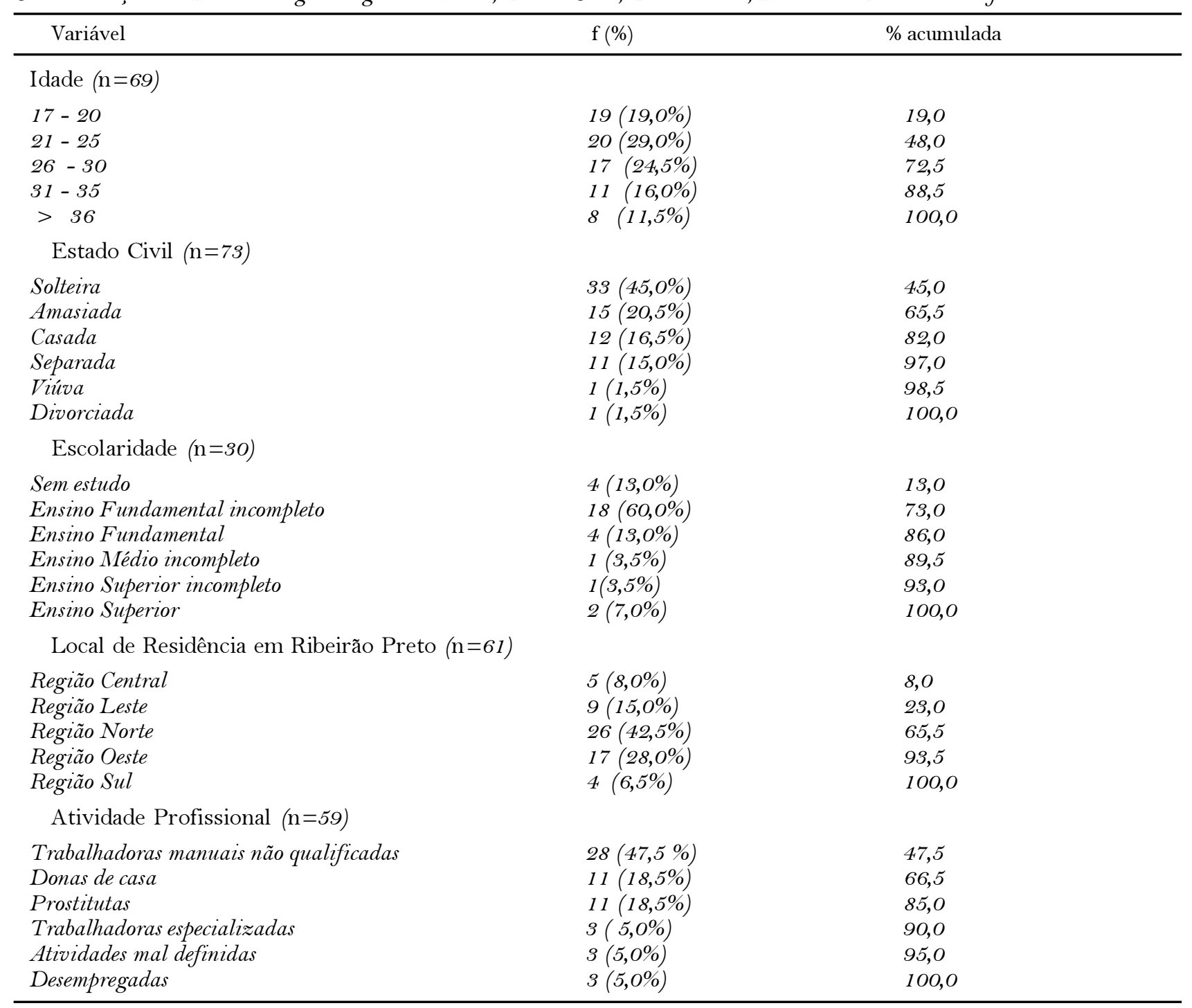


A informação com relação ao estado civil dessas mães foi obtida em 73 processos, em que consta que $45 \%$ eram solteiras, $15 \%$ separadas, $37 \%$ casadas ou amasiadas, e $3 \%$ foram casadas (divorciadas ou viúvas). A idade delas constou em 69 processos, sendo que $72,5 \%$ tinham entre $17 \mathrm{e}$ 30 anos.

A escolaridade foi um indicador pouco registrado. Considerando-se a amostra com essa informação ( $n=30), 73 \%$ dessas mães tinham, no máximo, oito anos de estudo. As 59 mães que tiveram suas atividades profissionais registradas realizavam, em sua maioria, trabalhos manuais não qualificados ou eram donas de casa. E, 72,5 \% delas residiam em bairros da zona norte e oeste da cidade, onde há maior concentração de chefes de família recebendo entre um e dez salários mínimos, segundo a Prefeitura Municipal de Ribeirão Preto (2003).

Em 20\% dos processos, os pais não tinham outros filhos além do entregue em adoção $(n=22)$. Em 19\% ( $n=21)$ não constava o registro deste indicador. $\mathrm{E}$, em $61 \%$ dos processos $(n=67)$, havia referências à existência de outros filhos dos pais biológicos. Nestes últimos casos, identifica-se que $45,5 \%$ dos pais biológicos possuíam até três filhos, além do entregue para adoção. Em 28 processos, indicava-se que essas crianças moravam com seus pais (mãe, pai ou casal), enquanto que em 18 diziam que aquelas moravam com outras pessoas (13 crianças viviam com parentes e cinco em abrigos) e em 21 deles indicavase que aquelas crianças também haviam sido entregues para adoção.

Os motivos para a entrega de seus filhos em adoção estiveram presentes em $61 \%$ dos processos, sendo que, muitas vezes, mais de uma justificativa foi apresentada. Em $47 \%$ dos processos, a entrega da criança foi relacionada à ausência de condições materiais para manter a criança; em $14,5 \%$, há relatos de falta de apoio familiar, em $16 \%$, referem-se à ausência de apoio do pai da criança; e, em 19,7\% dos processos, diferentes situações e motivos foram relatados. Esses motivos foram apresentados pelos próprios pais biológicos, pelos pais adotantes que tiveram contato com eles ou por profissionais da área da infância.

\section{Discussão}

Na análise dos 110 processos de adoção da Comarca de Ribeirão Preto, verificou-se que a adoção "pronta" é a modalidade (73\%) que mais ocorreu no período estudado. Ou seja, 80 adotantes procuraram o Fórum para regularizar a situação adotiva de uma criança que já se encontrava com eles. Esta criança, portanto, já tinha sido entregue aos pais adotantes pelos pais biológicos ou através da mediação de conhecidos, parentes ou até mesmo através de instituições. Esse resultado de maior ocorrência das adoções "prontas", em relação às outras modalidades de adoção, também foi verificado em estudos realizados em outras cidades brasileiras. Ayres (2005), em seu estudo sobre os processos de adoção $(n=190)$ na cidade do Rio de Janeiro, encontrou que $95 \%$ das adoções correspondiam a essa modalidade de adoção. E, Oliveira (2002), que anali- sou processos $(n=133)$ de um dos Fóruns da cidade de São Paulo, verificou que 63\% eram de adoções "prontas".

Os adotantes que realizaram as adoções "prontas", analisados no presente estudo, apresentaram as seguintes características: $44 \%$ das mulheres e $24 \%$ dos homens tinham entre 26 e 35 anos de idade, enquanto que $51 \%$ das mulheres e $60 \%$ dos homens estavam com mais de 36 anos; $64 \%$ dos adotantes tinham filhos e $31 \%$ dos adotantes não eram pais; $50 \%$ deles apresentaram como principal motivação para a adoção a vinculação existente com a criança e 35\% referiram-se à infertilidade ou problemas de saúde.

Esses dados nos fazem conjecturar sobre a existência de diferentes perfis de adotantes nas adoções "prontas": um que se aproxima das adoções realizadas pelos cadastrados, outro que se assemelha à "circulação de crianças", e, um eventual terceiro perfil que seria um resquício das adoções "à brasileira".

Parte desses adotantes visa à adoção de bebês e apresenta características e motivações muito semelhantes aos adotantes já cadastrados no Fórum - $31 \%$ não têm filhos e $35 \%$ apontam a infertilidade como motivação. Além disso, muitos deles ainda se encontram em idade reprodutiva ou são mais jovens que os demais requerentes das adoções "prontas". Porém, esses realizam a adoção "pronta" talvez como alternativa ao cadastramento nos Fóruns (tempo de espera prolongado para quem deseja adotar bebês; submissão aos estudos psicossociais e à avaliação do Juiz e do Promotor), por "al gumas possibilidades e crenças" que parecem permear essas adoções e que precisam ser melhor estudadas - "as negociações" feitas com a família biológica ou mediadores para se conseguir a criança; a oportunidade de "escolha da criança" pelos adotantes; o "acompanhamento" da mãe biológica na gestação e/ou no parto.

O fenômeno de circulação de crianças parece a nós, bem como a Ayres (2005), a gênese de grande parte das adoções "prontas". Esse fenômeno, estudado por Fonseca (2002), nos anos 80 e 90, contempla diferentes situações em que mães biológicas entregam seus filhos, mas sem perder completamente o status de mãe, mesmo que ocorra a disputa pela guarda da criança.

Nossa hipótese é de que uma das formas de adoção "pronta" constitui a legitimação na Justiça de uma relação já existente com a criança (vínculo de filiação) decorrente da entrega da criança pela mãe a vizinhos ou conhecidos. E a necessidade de legitimar essa vinculação parece estar relacionada com o fato de as relações estarem cada vez mais formalizadas, fazendo com que essa criança criada em família "substituta" precise, em vários momentos apresentar, diante das demandas da sociedade, documentos que comprovem essa vinculação e a guarda exercida pelo adulto, seja ao realizar viagens, seja ao ser matriculada em escolas, em atendimentos médicos ou ao ser inserida como dependente em algum plano previdenciário ao qual a família tenha direito. Dessa forma, crianças que antes viviam como filhos de criação, passam a ser requeridas como filhos adotivos na Justiça, para exercerem com maior facilidade direitos de cidadãos e adquirirem formalmente vínculos de filiação em relação às famílias que as acolheram. 
Nessa prática social, as crianças permanecem em um ambiente com características socioeconômicas e culturais não muito distintas das famílias de origem. As adoções que ocorreram segundo esse perfil foram realizadas por pessoas solteiras, ou casais que possuem filhos, que acabaram adotando legalmente uma criança, não por serem inférteis, mas pelo parentesco, pelo vínculo com a criança ou por conceberem como uma prática "comum" compartilhar a criação de uma mesma criança. Nos nossos dados, $50 \%$ adotaram por estarem vinculados à criança, muitos já tinham filhos adolescentes e adultos jovens e já não se encontravam mais em idade reprodutiva.

Uma outra hipótese que se formulou, a partir destes resultados em Ribeirão Preto e dos encontrados em outras cidades, sobre o alto índice das adoções "prontas", relaciona-se ao histórico das adoções no Brasil. Segundo Costa (1988, citado por Vargas, 1998), até 1988, 90\% das adoções que se concretizaram no país eram as chamadas adoções selvagens, mais conhecidas como "à brasileira". Ou seja, aquelas em que pessoas de qualquer estado civil registravam como próprios e legítimos filhos de outras. Com a promulgação do ECA (1990), estabeleceu-se a criação dos cadastros, tanto de adotantes como de crianças em condições de serem adotadas e o Judiciário passou a ser o responsável pela entrega da criança aos adotantes. Entretanto, após dezoito anos da criação do Estatuto, vários estudos mostram que a adoção através do cadastro do Fórum ocorre em menor número que as adoções "prontas" ou diretas. As adoções "prontas" não se caracterizam como crime, pois os adotantes não registram a criança como filho natural, como nas adoções "à brasileira". Porém, há mecanismos semelhantes aos dessas adoções: há possibilidades de encontrar e escolher crianças; às vezes, é possível ter contato com a família biológica e obter maiores informações sobre sua história; há pessoas que medeiam essas adoções, auxiliando na procura de quem deseja doar um filho e de quem deseja adotar. Dessa forma, a ocorrência das adoções "prontas" parece estar fortemente relacionada com os resquícios da prática ilegal da adoção "à brasileira”. No entanto, esta modalidade de adoção adquire status de prática legalizada, pelo fato de os adotantes, depois de já estarem com a criança entregue a eles informalmente, procurarem pela Justiça para legitimarem a adoção.

Apenas 15,5\% das adoções foram concretizadas por requerentes cadastrados nos Fóruns. A principal motivação apresentada foi a infertilidade e outros problemas de saúde, como indicam os resultados dos estudos de Cassin (2000) e Pereira e Santos (1999) que analisaram fichas de cadastrados na cidade de Ribeirão Preto.

Ainda em relação aos adotantes, vale destacar os resultados sobre o perfil socioeconômico dos adotantes desta pesquisa. Foram encontradas altas porcentagens de adotantes com poucos anos de estudo e que realizavam atividades que exigem quase nenhuma especialização, principalmente entre os que efetivaram "adoções prontas": $30 \%$ tinham concluído o ensino fundamental, $12,5 \%$ realizaram o ensino médio e $14 \%$ tinham completado o ensino superior; $48 \%$ realizavam atividades de menor qualificação e $39 \%$ desempenhavam atividades especializadas. Por um lado, os resultados de Ribeirão Preto são semelhantes aos de Oliveira (2002), que analisou processos do Fórum de uma região de São Paulo, caracterizada pela grande porcentagem de moradores provenientes da região Nordeste do país, pertencentes às camadas médias e populares. Por outro lado, os resultados encontrados diferem do perfil encontrado por Weber (2003), que apresentou adotantes com características das camadas médias e altas da sociedade - $11 \%$ com ensino fundamental, $20 \% \mathrm{com}$ ensino médio e em média $40 \%$ concluíram o ensino superior; e, $12 \%$ realizam atividades que exigem o ensino fundamental, $21 \%$ realizam atividades que necessitam do ensino médio e $33 \%$ desempenham atividades que exigem ensino superior. Entretanto, o estudo de Weber possui, como variáveis importantes, a utilização de um longo questionário auto-aplicável e a técnica de "bola de neve" como forma de convidar os entrevistados, que podem ter levado à participação da pesquisa apenas pessoas com grau de escolaridade maior, visto que pessoas analfabetas ou com baixa escolaridade podem não ter tido condições de preencher os questionários. E a técnica da "bola de neve" pode ter levado pessoas de uma mesma camada social a responder ao questionário e a indicar conhecidos com características socioeconômicas semelhantes às suas.

No presente estudo, $70 \%$ das crianças tinham até um ano de idade e foram adotados mais meninos (60\%) do que meninas $(40 \%)$. Esses resultados são semelhantes ao que foi encontrado em outras pesquisas nacionais (Oliveira, 2002; Weber, 2003). O que podemos perceber é que, embora a lei atual garanta que as necessidades das crianças devam ser privilegiadas em detrimento às dos adultos, as adoções que vêm ocorrendo são marcadas pelos desejos e expectativas dos últimos - que requerem bebês com outras características almejadas (saudáveis, brancos, recémnascidos, entre outras). Enquanto isso, muitas crianças mais velhas continuam institucionalizadas, sem perspectiva de retornarem para suas famílias de origem ou de serem colocadas em famílias substitutas, por apresentarem características pouco desejadas - têm etnia negra, são maiores de dois anos, apresentam deficiências ou problemas de saúde ou formam grupos de irmãos.

Ainda em relação a estas crianças, em 16 processos $(14,5 \%)$ foi registrada alguma modalidade de violência, sendo que a maioria referia-se à negligência e à violência física. Esses resultados também foram encontrados em pesquisas recentes sobre a violência contra as crianças em famílias brasileiras, entre elas a realizada por Azevedo (2007) e Roque (2006). Estes estudos apontam o crescimento marcante do fenômeno da negligência e a necessidade de pesquisas mais aprofundadas que levem em consideração tanto as características das famílias nas quais ocorre tal fenômeno como o contexto sócio-histórico e cultural em que elas estão inseridas.

Em relação às famílias biológicas, os dados encontrados neste estudo caracterizam-nas como pertencentes às camadas populares, possuindo baixa escolaridade e de- 
sempenhando atividades que não exigem qualificação. Sessenta e sete pais têm filhos (61\%), além do que foi entregue em adoção no processo analisado. Observou-se que eles já fazem uso da rede de apoio para mantê-los, delegando o cuidado a parentes, instituições ou entregando-os para adoção. Os que encontraram a adoção como "al ter nativa" justificam que o fizeram por alguns motivos, entre eles a falta de rede de apoio para auxiliar no cuidado e educação de seus filhos (14,5\%) e dificuldades materiais (47\%). Ochotorena (1996), ao estudar diferentes modelos etiológicos das situações de maus-tratos infantis, indica que a ausência de rede de apoio é um dos fatores que possibilita a ocorrência dos mesmos. Amorós e Palácios (2004), ao acompanhar a reinserção da criança na família biológica após a ocorrência de maus-tratos, constatam que as famílias que contam com apoio familiar e/ou comunitário têm maiores chances de reaverem seus filhos. Na decisão de entregar um filho em adoção, a rede de apoio também parece ser um dos aspectos fundamentais.

A falta de dados sobre as famílias biológicas nos processos não permitiu uma melhor compreensão das características e da dinâmica dessas famílias. No entanto, essa ausência em si já é um dado que aventa a hipótese de que nem todas as medidas estão sendo tomadas a fim de conhecê-las e averiguar se representam reais riscos ao desenvolvimento de seus filhos. Além disso, as informações existentes apontam para uma grande porcentagem de afirmações sobre a falta de recursos materiais e rede de apoio influenciando na entrega de seus filhos. Esses fatores não justificam a perda do poder familiar e a colocação em família substituta, de acordo com o ECA (1990), o qual determina que a ausência de recursos materiais não pode implicar na perda do poder familiar.

Esses dados nos remetem à ausência de políticas públicas, tanto para a manutenção da criança na família como para a sua reinserção nesta após abrigamentos. Além da ausência de ações governamentais, as políticas e as medidas voltadas para a família existentes são marcadas pelo assistencialismo e não para o desenvolvimento da auto-nomia e das potencialidades da população, bem como do exercício da cidadania (Ayres, 2005; Becker, 2002; Takashima, 2002). O que faz com que muitas dessas famílias biológicas se concebam como «incapazes» de manter seus filhos e encontram na entrega para adoção uma alternativa. Segundo Ayres, essa concepção também é veiculada em muitas campanhas pelas ONGs, pelo discurso dos profissionais, entre eles, o do psicólogo, que enfatiza como solução das crianças abrigadas a colocação em famílias substitutas, além do discurso de natureza políticomilitante que, através de campanhas, propagam a idéia de programas de adoção.

Um estudo vem nos mostrar a dificuldade que essas mães e famílias encontram para ter acesso a um dos muitos direitos para a manutenção de seus filhos junto delas. Rossetti-Ferreira, Ramon e Silva (2002) apresentam dados significativos baseados em pesquisa realizada pela Fundação Instituto Brasileiro de Geografia e Estatística
(FIBGE) sobre o uso de creches e pré-escolas pela população brasileira.

O estudo que as autoras apresentam demonstra que o acesso à educação infantil está diretamente relacionado à renda familiar e à escolaridade materna, tanto para a criança de zero a três anos como para as de quatro a seis anos. Os dados referem-se a lares das regiões Nordeste e Sudeste, que cobrem $70 \%$ da população brasileira, verificando que, entre as crianças de quatro a seis anos matriculadas nas pré-escolas, apenas $35 \%$ eram provenientes de lares pobres, enquanto $84 \%$ das crianças eram pertencentes aos $20 \%$ dos lares mais ricos. Em relação às crianças matriculadas de zero a três anos, os índices são $2 \%$ para os mais pobres e $35 \%$ para os mais ricos. As diferenças aumentam quando se considera o nível de escolaridade materna. Quase todas as crianças cujas mães têm grau universitário freqüentam pré-escolas e a maioria delas já está matriculada desde os primeiros anos de vida. Em contraste, menos de 50\% das crianças, cujas mães têm escolaridade inferior a quatro anos, freqüentam pré-escolas, e a porcentagem cai para $3 \%$ quando a criança tem menos de três anos de idade.

\section{Comentários Finais}

Os resultados dessa pesquisa apontam para a necessidade de aprofundamento de estudos que investiguem, nos grupos em que ocorrem entregas de crianças para adoção, a conjunção de fatores socioeconômicos e aspectos psicológicos, inclusive a estrutura familiar, rede de apoio e relacionamento conjugal. Essa análise poderá permitir uma melhor compreensão dos motivos dessa entrega, assim com indicar formas possíveis de preveni-las. O dado de que, em $47 \%$ dos processos, a ausência de condições materiais foi referida como justificativa para a entrega de crianças para a adoção, já aponta para a ausência e/ou ineficiência de políticas públicas que favoreçam a manutenção e o desenvolvimento da criança na família, conforme exigido pelo ECA (1990). Essa situação de desamparo freqüentemente fragiliza as famílias, tornando-as mais necessitadas de acolhimento de várias ordens. Ademais, tais estudos podem auxiliar na formação e orientar a atuação dos profissionais envolvidos, em relação aos aspectos psicológicos, sóciohistóricos e culturais que permeiam esse cenário.

Outro aspecto importante que observamos, em nossa amostra de processos judiciais, é que o processo de entrega de criança é uma prática silenciada, que ocorre, muitas vezes, sem o acompanhamento da Justiça e da equipe interprofissional, com indícios de arrependimento, coação e até "pagamento" dessas famílias biológicas.

$\mathrm{Na}$ maioria dos processos, principalmente de adoções "prontas", pareceu-nos inviabilizado o contato da Justiça com as famílias biológicas - através da apresentação de termos de consentimento da adoção já assinados pelos pais biológicos e da não disponibilização de informações sobre o local em que eles se encontram. Dessa forma, os processos de destituição do poder familiar ocorrem sem a apre- 
sentação das famílias biológicas em audiência, o que impossibilita a investigação dos reais motivos da adoção e da escolha do casal para o qual entregaram seu filho. Considerando essas complexas relações, acreditamos na importância de um estudo mais aprofundado sobre as adoções «prontas».

\section{Referências}

Amorós, P., \& Palácios, J. (2004). Los protagonistas y los fatores clave em el acogimiento familiar. In Acogimiento familiar. Madrid, España: Alianza.

Ayres, L. S. M. (2005). De menor a criança, de criança a filho: Alguns discursos da adoção. Tese de Doutorado não-publicada, Programa de Pós-Graduação em Psicologia Social, Instituto de Psicologia, Universidade Estadual do Rio de Janeiro, RJ.

Azevedo, M. A. (2007). Pesquisando a infância e a violência doméstica no Brasil contra crianças e adolescentes. A ponta do iceberg. Brasil 1996 a 2006. Retirado em 05 mar. 2007, de http:// www.ip.usp.br/laboratorios/lacri/index 2.htm

Becker, M. J. (2002). A ruptura de vínculos: Quando a tragédia acontece. In S. M. Kaloustian (Ed.), Família brasileira, a base de tudo (5. ed., pp. 60-76). São Paulo, SP: Cortez.

Brito, L. M. T., \& Diuana, S. (2002). Adoção por cônjuge. Reais vantagens, quando? Revista Brasileira de Direito da Família, $13(4), 42-60$.

Cassin, W. C. (2000). O psicólogo judiciário e a cultura da adoção: Limites, contribuições e perspectivas. Dissertação de Mestrado não-publicada, Faculdade de Filosofia, Ciências e Letras de Ribeirão Preto, Universidade de São Paulo, Ribeirão Preto, SP.

Estatuto da Criança e do Adolescente. (1990). Lei Federal 8069/ 90 de 13/07/1990. Brasília, DF: Ministério da Justiça.

Fonseca, C. (2002). Caminhos da adoção (3. ed.). São Paulo, SP: Cortez.

Freston, Y. M. B., \& Freston, P. (1994). A mãe biológica em casos de adoção: Um perfil da pobreza e do abandono. In F. Freire (Ed.), Abandono e adoção. Contribuições para uma cultura da adoção II (pp. 81-90). Curitiba, PR: Terre des Hommes.

Mariano, F. N. (2004). O cenário jurídico: $A$ análise de processos de adoção no município de Ribeirão Preto (1991-2000). Dissertação de Mestrado não-publicada, Faculdade de Filosofia, Ciências e Letras de Ribeirão Preto, Universidade de São Paulo, Ribeirão Preto, SP.

Ochotorena, J. P. (1996). Explicaciones etiológicas de las diferentes situaciones de maltrato y abandono infantil. In J. P. Ochotorena \& M. I. A. Madariaga (Eds.), Manual de protección infantil (pp. 25-62). Barcelona, España: Masson.

Oliveira, N. G. S. (2002). Padrões de adoção: Reinterpretação à luz da perspectiva etiológica. Tese de Doutorado nãopublicada, Instituto de Psicologia, Universidade de São Paulo, SP.

Pereira, J. M., \& Santos, M. A. (1999). O enfoque psicológico da adoção: Revisão da literatura. In R. C. Labate (Ed.), Caminhando para a assistência integral (pp. 225-247). Ribeirão Preto, SP: Scala.

Prefeitura Municipal de Ribeirão Preto. (2003). Dados Censo 2000 IBGE, por setores e unidades censitárias. Ribeirão Preto, SP: Autor.

Roque, E. M. S. T. (2006). Estudos das famílias de crianças e adolescentes, vítimas de violência, que sofreram intervenção da justiça, em Comarca de Vara única - Estado de São Paulo - Brasil. Tese de Doutorado não-publicada, Escola de Enfermagem de Ribeirão Preto, Universidade de São Paulo, Ribeirão Preto, SP.
Rossetti-Ferreira, M. C., Ramon, F., \& Silva, A. P. S. (2002). Políticas de atendimento à criança pequena nos países em desenvolvimento. Cadernos de Pesquisa, 115, 65-100.

Santos, M. A., \& Pereira, J. M. F. (1999). A interface entre as abordagens psicológica e legal da adoção. In R. C. Labate (Ed.), Caminhando para a assistência integral (pp. 307-330). Ribeirão Preto, SP: Scala.

Silva, N. N. (1998). Amostragem probabilística: Um curso introdutório. São Paulo, SP: Editora da Universidade de São Paulo.

Takashima, G. M. K. (2002). O desafio da política de atendimento familiar: Dar vida às leis - Uma questão de postura. In Família brasileira, a base de tudo (5. ed., pp. 77-92). São Paulo, SP: Cortez.

Vargas, M. M. (1998). Adoção tardia. Da família sonhada à família possivel. São Paulo, SP: Casa do Psicólogo.

Weber, L. N. D. (2003). Pais e filhos por adoção no Brasil. Características, expectativas e sentimentos. Curitiba, PR: Juruá. 